\title{
Successful fast-track cooperation towards environmental action: three coproduction cases in Mexico City
}

\author{
M. Montelongo A. \& R. P. M. Wittek \\ Department of Sociology, University of Groningen, The Netherlands
}

\begin{abstract}
Local organizations can play a decisive role in implementing environmentally friendly collective practices in urban communities. Many initiatives fail, however. One possible way to reduce the number of failures is to develop understanding of cooperation processes to answer the question of why some coproduction initiatives involving relationships between local actors and external organizations are successful. We argue that answering this question requires a closer look at the sequence in which co-productive actions unfold. According to the behavioural assumptions underlying Ostrom's influential work on collective action, successful cooperation follows a pattern of bottom-up self-organization: in settings where interdependent stakeholders have the opportunity to communicate, reciprocal exchanges will eventually foster the development of trust, reciprocity, and reputation, which in turn provide the foundation for collective action. The present investigation examines to what degree this hypothetical sequence also holds for collective action among members in urban communities and what is the consequence for sustainability related coproduction processes. For that purpose, we draw on a multi-method comparative case study of the successful implementation of Water Collector Systems in three low-income neighborhoods in Mexico City in 2014. The findings suggest that rather than emerging spontaneously, community leaders, external stakeholders and past successful experiences with cooperation play a critical role in fostering present and future collective action. Moreover, there is no conclusive evidence that durable patterns of trust, reciprocity, and reputation emerged among community members at any stage of the process.

Keywords: coproduction, leadership, collective action, cooperation, case study.
\end{abstract}




\section{Introduction}

Local organizations can play an important role in helping governments in achieving sustainable development. In spite of the potential benefits that could be made from a coproduction process during which an external organization works together with a given community towards the production of services, many of such initiatives fail when it comes to their implementation or maintenance. Often, such failures result from poor understanding of local conditions. A better understanding of the conditions contributing to successful coproduction processes is particularly important in low-income urban communities in low- and middle-income countries, where there is a combination of limited access to basic services and overcrowding. This paper looks at the conditions under which coproduction processes between external and local actors in low-income urban communities are successful. The main purpose of this study is to have a closer look at the sequence in which coproduction actions unfold and to disentangle how the different stakeholders -in particular the external organization and the community leaderaffect the success of the process.

The literature on cooperation has made great advances in the understanding of mechanisms that contribute to successful cooperation. It is normally assumed that cooperation is the end result of an interaction process between participants. In this line, Ostrom [1] develops a theoretical model in which face-to face communication may foster the development of trust, reciprocity, and reputation, which in turn provide the foundation for collective action. This model explains why communication can be a key to effectiveness within the cooperation process. However, it assumes only one sequence and the role of third parties is not clear. Although stakeholder participation has been widely treated in the literature of coproduction, it mostly concerns the importance of citizens' involvement in the decision making process $[2,3]$ and the role of public authorities facilitating participation in medium-and long-term initiatives involving production and provision of public services [4]. When referring to the specific roles and functions of stakeholders in the process, the literature distinguishes between roles related to the design and provision phases respectively [5], or devotes attention to western cases [6]. Little is known about the cooperation sequence leading to successful sustainability -related coproduction processes in low income urban communities and what role the different stakeholders play in the process. Moreover, little is known about the conditions for success when there is little time to build cooperative mechanisms among participants.

Drawing on a multi-method explorative qualitative case study approach on three urban low income communities in Mexico City, carried out in 2014, this article explores to what degree the cooperative sequence proposed by Ostrom explains successful implementation of Water Collector Systems (WCS) in these communities and what role the different parties play in the cooperation process. We claim that third parties may be an important trigger to get the cooperation going in the first place, suggesting that Ostrom's model relies too much on the idea of emergent spontaneous self-organization, which is not always granted. 
This research makes at least three distinct contributions. First, based on qualitative research, this study provides in-depth insights into the conditions contributing successful coproduction processes in urban communities, delineating the scope of the analyzed theoretical model and providing real life evidence for its further improvement. Second, while previous research has focused on long term coproduction processes, our study elaborates on conditions fostering successful short term coproduction processes. Third, with its focus on urban low income communities in a lower-middle income country, the findings of this study contribute to the development of effective policies in similar contexts.

The paper begins by outlining the coproduction concept. We then briefly sketch the tested model, highlighting its main assumptions about the sequence for collective action and elaborating on the expected influence of both, the leader and the organization on the coproduction process. This is followed by a description of the research design and key characteristics of the three case studies. Next, three case studies are presented. The last section contains a discussion of our findings.

\section{Theoretical framework}

A community's ability to take collective action is a key factor in achieving sustainable development [7]. Socialization is the process within which individuals interact and it's broadly recognized precondition for the further development of inter-personal relationships which in turn facilitate collective action [8]. In this way, collective community action can be assumed as the result of a bottom-up process in which mutual interaction among community members leads to community organization.

In order to answer the research question concerning the sequence leading to successful fast track cooperation and the role of the different stakeholders in the process, this study draws on the theoretical model of collective action developed by Ostrom [1], which includes some of the most influential cooperative mechanisms during the last decades. One of the key assumptions of the model is that face to face communication facilitates the development of trust, reciprocity and reputation among participants, which in turn provide the basis for collective action. Before presenting the model, we first introduce the concept of coproduction.

\subsection{Coproduction}

Coproduction is defined here as a "process through which inputs from individuals who are not in the same organization are transformed into goods and services" [4]:1073. Coproduction processes include activities ranging from the management of large-scale public infrastructure assets, such as power generators, water, and public housing [3] to small and medium-sized community-based projects such as recycling programs or recreational activities [5] and usually involve cooperation processes between local and external actors. By including the participation of community members, those processes can be seen as an opportunity to strengthen the horizontal patterns of interaction within the community, reinforcing the sense 
of community among participants [6]. Whereas norms compliance, and the notion of collective identity involving shared understandings will facilitate the work of external organizations operating in the field [9], coproduction processes can be hampered by differences in values, interests, responsibilities and incentives among participants or as a result of the lack of effective participatory process [5].

\subsection{A theoretical model for collective action}

Compliance with the social norms and rules is closely linked to successful cooperation. Social norms are informally enforced rules, which represent internal individual's valuation about what is supposed to do [10] while rules can be (legally) enforced [1]. According to Ostrom, in settings that provide favourable conditions for face-to face communication, reciprocal exchanges will eventually foster the development of trust, reciprocity, and reputation, which in turn provide the foundation for collective action. Reciprocity is a social norm that anticipates positive reactions coming from positive reactions and negative reactions coming from negative reactions. Social norms are acquired within specific social context; therefore individuals make decisions concerning their use based in previous experiences. In this way, decisions of individuals facing social dilemmas in which they must decide how much of a common resource to take for themselves, are connected to positive or negative previous experiences. Trustworthiness about reciprocity is the reason for activating cooperation resulting in a multiplier spin. When reciprocity becomes a norm and is used by many individuals, participants find an incentive for building up reputation. Trust, reciprocity and reputation positive effect will hold together and reinforce each other for as long as the originating conditions prevail. The symmetrical conditions of interest, resources and benefits are conditions facilitating cooperation processes by providing participants with equal conditions for participation.

In sum, the model establishes that continues interaction enables individuals to recognize other individuals with similar norms and to increase trustworthiness on them, which in turn encourage the development of reciprocity and reputation. Activation of cooperation mechanisms eventually trigger a willingness to cooperate:

Face to face communication $\rightarrow$ Trust, Reciprocity, Reputation $\rightarrow$ Cooperation

Without denying the importance of interaction in cooperative mechanisms formation, we argue that thirds parties may be an important trigger to get cooperation going in the first place. This claim is based in the observation that there are successful short-term coproduction processes where it is difficult to develop cooperative mechanisms among participants. The reminder of this section will therefore explore the role of the community leader and of the external actors in the coproduction process. We build upon functional leadership approach to explore how leaders create effective teams, while drawing on social entrepreneur's perspective to address the role of the external organization within a context of scarcity. 


\subsection{The leader, organizational commitment}

Successful performance of the group derives from the capacity of its members to successfully coordinate their individual actions in complex and dynamics environments in the long term. From a functional leadership perspective, an effective leader plays a key role towards effective team performance while diagnosing collective problems, generating and implementing solutions [11] According to the taxonomy by Fleishman et al. [12], leadership functions have four general dimensions $[11,12]$ :

1. Information search and structuring. In order to define collective objectives, complete high quality information from stakeholders in and outside the group is necessary. Monitoring and feedback on the implementation of problem solution is important in order to identify and solve the on-going problems. This is particularly important in a highly complex system, where unexpected problems arise.

2. Information use in problem solving. Once the necessities of the group have been identified and translated into concrete objectives, it's necessary to evaluate possible solutions in order to ensure that strategies may result in achievable objectives and in concrete action plans. An effective plan takes into consideration local conditions and resources.

3. Managing personnel resources. It refers to activities involved in the implementation of the action plan. Important activities include motivate individuals to increase social cohesion, allocate particular tasks according to particular skills and monitor activities to ensure compliance with established rules, regulations and timeframes.

4. Managing material resources. Successful implementation of the action plan implies the supply and maintenance of material resources. The lack of such resources will severely undermine the success of the project, regardless of the team motivation or leadership skills.

\subsection{The Organization, looking for investment opportunities}

Social Enterprise Organizations (SEOs) have been seen as an alternative to complement the efforts of the governments to meet the basic needs of the local population. This form of local entrepreneurship clearly targets poverty-related needs at community level [9]. One of the main tasks of SEOs is to identify, and later exploit local opportunities in order to improve local living conditions [9, 13]. This often implies the adaptation of the organization to meet local market conditions and needs [13]. A good understanding of local rules, credibility, access to material and social resources to perform the action, and to deliver valuable resources for community members are basic requirements that have to be meet by the SEOs if they are to reduce poverty while becoming a successful enterprise [9]. By creating local opportunities and contributing to the local economic and social development, SEOs contribute to sustainable development [14]. Their influence and contribution in this respect even includes changes in the social local structure. This includes for example economic and therefore social empowerment of women [9]. 
According to the information above, we formulate the following general proposition: The likelihood for successful fast track coproduction processes will be higher in communities where leader(s) and external organizations are involved, since third parties may affect the sequence in which cooperation unfolds.

\section{Research design and data}

Study cases were selected to elucidate conditions that facilitate coproduction processes between an external organization and local community members, on the basis of theoretical sampling [15] that is, we aim to replay or extend the former theoretical framework. Communities with meaningful participation levels in the coproduction process and members that assume leadership roles were selected. A multi-method comparative approach was used. Observational, interview, video, and survey data was collected in three urban low income communities in Mexico City in 2014. Direct observation was performed at irregular intervals over a period of two months, including through conversations with community leaders and community members. Computer mediated communication was maintained with one expert in urban development social processes and the Managing Director of the organization involved. Finally, a total of 198 paper surveys were applied.

Community 1 (Quiltepec) is located in Tlalpan. Communities 2 (Tehuixtitla) and 3 (Tecalipac) are located in Xochimilco. All three communities are located in environmental protected areas grounds, in high-risk areas and/or inaccessible places, consequently with no access to basic resources. Cooperation in this work is basically related to the purchase of water collector systems (WCS) been featured by the external organization involved. The work motto of the organization is to deal with communities instead of individuals alone. Therefore, participation of different neighbors was needed in order to lunch the project. Survey data shows that members of the three communities have had high levels of previous cooperation experiences, as well as a high-level of commitment to participate in present and future actions. However, there is no conclusive evidence regarding the development of trust among participants (see Table 1).

\section{Case studies}

We first briefly describe the key characteristics of the leader and the organization. We then identify their role before, during and after the coproduction process. Our primary focus is the implementation phase. However, elements of provision phase are also included.

The leader. In general, two types of leaders can be distinguished: the community leader who lives in an unorganized community and is responsible for guiding and coordinating the different processes within the community, and the leader who serves as an interface between external organizations and semiorganized communities in order to obtain political benefits.

The organization. Urban Island was established in order to meet water needs in low income communities. It has experienced a steady and healthy growth since it was founded in 2009. Since Urban Island does not have permanent funding, WCS 
supply is irregular. It is standard practice for urban island to train and then using community members as installers of WCS.

Table 1: $\quad$ Participation and trust.

\begin{tabular}{|l|l|l|l|}
\hline & $\begin{array}{l}\text { C1-Quiltepec } \\
\mathrm{n}=12 / 12 \mathrm{HH}\end{array}$ & $\begin{array}{l}\text { C2-Tehuixtitla } \\
\mathrm{n}=136 / 230 \mathrm{HH}\end{array}$ & $\begin{array}{l}\text { C3-Tecalipac } \\
\mathrm{n}=50 / 180 \mathrm{HH}\end{array}$ \\
\hline Past participation (\%) & & & \\
\hline Yes/No & $91.7 / 8.3$ & $90.2 / 9.8$ & $91.8 / 8.2$ \\
\hline Present participation (\%) & & & \\
\hline Yes/I could not/I don't wanted & $91.7 / 8.3 / 0$ & $27 / 71.4 / 1.6$ & $35.4 / 47.9 / 16.7$ \\
\hline $\begin{array}{l}\text { Frequency of participation } \\
\text { A few times a week/a month/year }\end{array}$ & $16.7 / 50 / 16.7$ & $29.5 / 41.7 / 12.1$ & $26.1 / 34.8 / 30.4$ \\
\hline Future participation (\%) & & & \\
\hline $\begin{array}{l}\text { To become energy producers } \\
\text { Yes/may be/no }\end{array}$ & $66.7 / 33.3 / 0$ & $71.4 / 24.1 / 4.5$ & $84 / 16 / 0$ \\
\hline $\begin{array}{l}\text { In environmental educational program } \\
\text { Yes/may be/no }\end{array}$ & $75 / 25 / 0$ & $89.5 / 9.8 / 0.8$ & $92 / 6 / 2$ \\
\hline Inclusive decision making process (\%) & & & \\
\hline Yes/I am not sure/no & $83.3 / 16.7 / 0$ & $60.0 / 15.7 / 24.3$ & $66.7 / 8.3 / 25$ \\
\hline Social networks and trust (\%) & & & $19.5 / 31.7 / 17.1$ \\
\hline $\begin{array}{l}\text { Trust in suppliers of ecological techniques } \\
\text { Always/mostly/sometimes }\end{array}$ & $44.4 / 33.3 / 22.2$ & $18.1 / 24.8 / 33.3$ & \\
\hline $\begin{array}{l}\text { Trust in neighbours } \\
\text { Always/mostly/sometimes }\end{array}$ & $8.3 / 8.3 / 58.3$ & $12.5 / 23.4 / 44.5$ & $17 / 17 / 40.4$ \\
\hline $\begin{array}{l}\text { Trustable neighbours } \\
\text { Most/many/some }\end{array}$ & $45.5 / 9.1 / 27.3$ & $34.6 / 10.2 / 23.6$ & $46 / 8 / 22$ \\
\hline
\end{tabular}

\subsection{Before the coproduction process}

Community 1 (Quiltepec). In this community, we could establish contact with two outgoing leaders who had leaded diverse collective activities in previous years: the construction and paving of a street passage for accessing the community, (illegal) electricity cabling, as also a safeguard in the area was organized against frequent robbery. All these activities entailed in turn different processes. For instance, the construction of the street passage started with a roadblock with the aim to secure the local authority's permission to paving the street. Once the permits were obtained, collective action included participation of community members with handwork for paving. During the process, the leader(s) organized meetings to distribute roles and administrative tasks among community members. The reduced number of families and the fact that they all were family related eased the transmission of information concerning organization processes through faceto-face communication. After a leader contacted the Urban Island, the coproduction process started.

Community 2 (Tehuxtitla). In this community we found one female lieder who organized collective actions involving strong negotiation processes with local authorities, such as: land regulation, streets paving, telephone services, and electricity cabling. Community members participated with handwork in all mentioned activities. Groups that undertook surveillance rides to prevent 
telephone wire or public light bulbs robberies, as well as workshops were also organized. During data collection, an ongoing contest for women wishing to lose weight lunched by the leader had been started. We found an efficient communication, monitoring and sanctioning system within the community. Regarding communication, street managers were assigned by the leader for maintaining links with the rest of the neighbors. Additionally, information ads are stuck on telephone boards at the street entrance. Regarding monitoring and sanctions, community members informed the leader on faults that according to its severity resulted in interruption of the telephone service as a temporary penalty. The contact between the leader and Urban Island was established throughout a third person who was working in the local government offices.

Community 3 (Tecalipac). In this community there is a community board whose members help to coordinate collective activities on an irregular but solid basis. Past collective activities include: electricity cabling, streets paving and actions to improve local security. We found an effective communication system that includes regular meetings, information boards at the main street entrance and the chapel bell that rings when necessary to bring everyone together. The contact between one of the community board members and Urban Island was established by the same person who established the contact with Tehuixtilta, suggesting that such a person may be a local leader who serves as a liaison between local organizations and semi-organized communities.

\subsection{During the coproduction process}

The process of water collector systems installation started in year 2012 in Tecalipac, in 2013 in Quiltepec and in 2014 in Tehuixtitla. Participation scheme included an economic contribution from the user's side in all cases. In communities with an outgoing leader(s) all necessary organization tasks previous to water collector's installation were in charge of the leader and the organization, including a meeting for the project's presentation, registration of potential users, fee collection and the planning for materials and equipment delivering. In order to approve an application, the organization was responsible to verify that the roof of the dwelling fulfilled the necessary technical requirements. The leader, together with the organization was in charge of the human resources management during the arrival of the WCS stock to the community. From then on, the organization made decisions concerning storage, planning equipment's installation in selected dwellings, and supervision of the systems functioning. During implementation process, new community members give notice of their wish to take part in the project. In this way, new groups of future users are formed. In Tecalipac community, without evident leader, members of the community board participated along the implementation phase in different ways. For instance, they planned the meeting for the project to be introduced and organized the event. However, the organization was responsible for most of the activities involved in the process. Despite of unlimited access to information channels within the community, each application is processed individually, and the process is therefore very lengthy. Presently, all dwellings in Quiltepec now have access to a reliable supply of clean 
water, while the installation process of WCS in the other two communities is still going on.

\subsection{After the coproduction process (provision phase)}

Once the WCS has been installed, the organization is responsible for training users for equipment use and regular maintenance. Thus, provision phase is carried out by community members, who can contact the organization if problems arise. Satisfactory work process in Quiltepec, motivated community members and organization to extend the project to other green technologies such as treatment of clear gray water systems, and biodigesters for biogas production. Furthermore, an environmental program including theatre, and workshops in order to encourage the permanent adoption of the different green technologies. All these activities have been carried out also in the other two communities but to a lesser extent.

\section{Discussion and conclusions}

In this exploratory study we show the value of local conditions in coproduction processes. Bottom-up self-organization processes in communities where continuous interaction facilitates cooperation is widely accepted. Following this line, the collective action theoretical model developed by Ostrom, shows that in the presence of structural favorable conditions, face-to-face communication facilitates the development of trust, reciprocity and reputation among participants, which in turn provide the basis for collective action. However, any of the analyzed case studies in this study accomplished the cooperation sequence intended for this model. Our analysis shows a quite different sequence, where local leaders and external organization play a central role in starting and coordinating cooperation processes. Moreover, concluding evidence related to formation of reported cooperative mechanisms among community members was not found at any stage of the process. The analysis of the case material leads to the following general conclusions:

First, our research shows that shortage of resources within communities result in the outcome of local leaders. These late usually identify community necessities, organize and coordinate the necessary processes to accomplish them. In both communities with an outgoing leadership, we found a large number of collective activities organized by the leader(s) aimed to introduce or improve basic services in the community. As part of the organizing leader's activities we observe the set up of communication channels within the community. This communication system allows the leader handled more smoothly and quickly the different collective actions. Our analysis suggests that a leader with organizational skills combined with past successful cooperation experiences provide necessary conditions for future collective actions, including coproduction processes. This finding is in line with previous research, which has shown that successful experiences with cooperation increase project feasibility beliefs and therefore motivate cooperation. In this regard, our expectation was that successful past experiences with 
cooperation foster the development of trust among participants. However, outcomes of the surveys did not allow final conclusions on this matter.

Second, concerning the coproduction process, we found that local leaders acted as liaison between community members and external organization. Once the process started the leader gives some from his/her functions to external actors who conduct most part of the coproduction process. When leadership is diffuse, external actors' role and those information channels within the community gain significance. This is the case of the Tecalipac community, where we found diffuse leadership but effective communication channels that facilitated the process. Moreover, subjects in this community reported the highest willingness to participate in future projects and a relatively high degree of trust towards green suppliers. These results suggest that external organization's intervention strategy of building credibility based on local rules and offering valuable resources for community members is effective. In all cases, water collector system users are in charge of the provision phase -posterior to the implementation phase- and are responsible for the equipment maintenance in the long run. The case material allows us to elucidate conditions which may influence the permanent adoption of the green technology, which are outlined below.

Third, the external organization plays a crucial role regarding the permanent adoption of the WCS. By involving technical aspects, the organization is responsible for the right setting up and functioning of the equipment. It is also responsible for training users in the future maintenance of equipment as also providing alternatives to solve potential problems. The organization's practice of training community members as installers shows its perception and response abilities to local problems. What may be more important than the operativetechnical aspects is the value that the WCS has for the users. If equipment lacks a value for the users, it is a responsibility of the leader and the organization to transmit it. In this regard, the regular local governmental policy of delivering equipment for free as exchange for political support undervalues equipment and deprives the local communities of experience a collective action process. Environment educational activities carried out by the organization before and after the setting up, sustain its response ability to the local conditions, which in turn enable it to build reputation and therefore to expand its activities in the area.

Finally, and regarding a lack of resources, results are ambivalent. The work of the organization would be affected by the lack of financial resources. In the same way, a lack of resources prevents community member's participation, which blocks the coproduction process to be executed in one sole stage. As a result, the relationship between external actors and community members is lengthened. The continuous presence of the organization in a given community, allows the strengthening of cooperative mechanisms between the external organization and community members, resulting in a greater participation of community members and the development of new projects. This process is exemplified in Quiltepec, where the coproduction process was scaled up for other green technologies. Once any green technology is installed, the lack of financial resources from the side of the users or the organization to solve technical problems will result in the end of the use of the technology. 
Before concluding, at least three limitations need acknowledgment. First, our study focused on a limited selection of communities. They are also specific to particular context, which limits the generalization of our findings. Second, analysis was mainly geared to generate knowledge on the role of leaders and external actors in the cooperation sequence. Future research should explore the relationships linking leader's and external actor's actions with the formation of cooperative mechanisms among community members, which involves the study of the community governance structure. Leader personality traits must influence her/his relationship with the community members, and the external organization. Moreover, leader personality traits may be crucial factor in her/his decision to participate in sustainability-related coproduction processes, and therefore deserves more attention. Third, different organizations may differ on their choice of intervention strategies, and therefore there is a need for future research.

In spite of these limitations, our study cases clearly show that traditional conceptions that assume an organization bottom-up process are not always applicable. Our findings pointed out to leaders and external organization as initiators and coordinators of the cooperation process. Thus, cooperation during coproduction process was not the end product of a relationship based on trust, reciprocity and reputation but a kick-start action that facilitates the development of such mechanisms. Moreover, our study shows the value of community leaders' and external organizations' abilities for reacting to local conditions towards successful coproduction process.

\section{References}

[1] Ostrom, E. Crossing the great divide: coproduction, synergy, and development. World development, 24(6), 1073-1087, 1996

[2] Percy, S. L. Citizen participation in the coproduction of urban services. Urban Affairs Review, 19(4), 431-446, 1984

[3] Wiewiora, A., Keast, R., \& Brown, K. Opportunities and challenges in engaging citizens in the co-production of infrastructure-based public services in Australia. Public Management Review, 1-25, 2015

[4] Ostrom, E. A behavioral approach to the rational choice theory of collective action: Presidential address, American Political Science Association, 1997. American political science review, 92(01), 1-22, 1998

[5] Bovaird, T. Beyond engagement and participation: User and community coproduction of public services. Public administration review, 67(5), 846860,2007

[6] Sundeen, R. A. Coproduction and Communities Implications for Local Administrators. Administration \& Society, 16(4), 387- 402, 1985

[7] Lehtonen, M. The environmental-social interface of sustainable development: capabilities, social capital, institutions. Ecological economics, 49(2), 199-214, 2004

[8] Cousins, P.D., Lawson, B., Squire, B. Performance measurement in strategic buyer supplier relationships: The mediating role of socialization 
mechanisms, International Journal of Operations \& Production Management, 28(3), 238-258, 2008

[9] Seelos, C., Mair, J., Battilana, J., \& Dacin, M. T. The embeddedness of social entrepreneurship: Understanding variation across local communities. Research in the Sociology of Organizations, 33, 333-363, 2011

[10] Lindenberg, S., \& Steg, L. Goal-framing theory and norm-guided environmental behavior. In H.C. M. van Trijp (Ed.), Encouraging sustainable behavior, 37-54. New York: Psychology Press. 2013

[11] Zaccaro, S. J., Rittman, A. L., \& Marks, M. A. Team leadership. The Leadership Quarterly, 12(4), 451- 483, 2002

[12] Fleishman, E. A., Mumford, M. D., Zaccaro, S. J., Levin, K. Y., Korotkin, A. L., \& Hein, M. B. Taxonomic efforts in the description of leader behavior: A synthesis and functional interpretation. The Leadership Quarterly, 2(4), 245-287, 1992

[13] Zahra, S. A., Rawhouser, H. N., Bhawe, N., Neubaum, D. O., \& Hayton, J. C. Globalization of social entrepreneurship opportunities. Strategic entrepreneurship journal, 2(2), 117-131, 2008

[14] Seelos, C., \& Mair, J. Sustainable development: How social entrepreneurs make it happen, IESE Business School Working Paper No. 611, SSRN, 2005

[15] Eisenhardt, K. M. Building theories from case study research. Academy of management review, 14(4), 532-550, 1989 